\title{
$\mathbb{A}$ Economics Bulletin
}

\section{Volume 33, Issue 1}

\section{Is Big Brother Watching Us? Google, Investor Sentiment and the Stock Market}

\author{
Francisca Beer \\ California State University, San Bernardino \\ Fabrice Hervé \\ University of Burgundy, France \\ Mohamed Zouaoui \\ University of Burgundy, France
}

\begin{abstract}
This paper proposes a novel measure of French investor sentiment based on the volume of internet search reported by Google Trends. We find that our sentiment indicator correlates well with alternative sentiment measures often used in the literature. Furthermore, we find that investor sentiment influences the behavior of mutual fund investors. The results also reveal evidence about short-run predictability in return. An increase in our sentiment index leads to shortterm return reversal. The reversal pattern is more pronounced for smaller firms than larger firms, consistent with the predictions of noise trader's models.
\end{abstract}

I would like to thank the Editor, an anonymous referee and Mickaël Clévenot for useful suggestions and comments. I also wish to thank the seminar participants at FARGO (University of Burgundy) for their valuable comments.

Citation: Francisca Beer and Fabrice Hervé and Mohamed Zouaoui, (2013) "Is Big Brother Watching Us? Google, Investor Sentiment and the Stock Market", Economics Bulletin, Vol. 33 No. 1 pp. 454-466.

Contact: Francisca Beer - fbeer@csusb.edu, Fabrice Hervé - Fabrice.Herve@u-bourgogne.fr, Mohamed Zouaoui - Mohamed.Zouaoui@ubourgogne.fr.

Submitted: January 19, 2013. Published: February 21, 2013. 


\section{Introduction}

Whether investor sentiment affects stock markets is a question at the center of a long-running debate in behavioral finance. Black (1986), De Long et al. (1990), Barberis et al. (1998), among others, have formally modeled the role of investor sentiment in the financial markets. These pioneering works are the source of an extensive empirical literature on the impact of sentiment on stock prices. Traditionally, investor sentiment can be measured either directly through survey-based indicators such as the American Association of Individual Investors survey and the University of Michigan Consumer Confidence survey or indirectly through market-based indicators such as closed end fund discount, mutual fund flows, data from IPOs and derivatives ${ }^{1}$. Each measurement technique has advantages and limitations.

Lazer et al. (2009) and King (2011) put forward the idea that technological developments - development of the Internet and social networks for instance - produce extremely rich data set allowing researchers to make significant progress in the exploration and understanding of human behavior, in particular individual moods. In this paper, we construct a novel measure of French investor sentiment based on the volume of internet search reported by Google Trends over the period 2004-20112. Dzielinski (2011) shows that Google search engine accounts for 70 percent of the total traffic involving research. In France, Google has continued to increase its market share. In January 2004, AT Internet reports that Google accounted for $68.2 \%$ of the total French internet traffic, $82.6 \%$ in January 2008 and $92.7 \%$ in December 2011, leading us to conclude that in the case of France the representativeness of the database is more than satisfactory.

There are numerous advantages to measuring investor sentiment using internet search data. First, the database is large, free, unrestricted, updated weekly and has high data frequency. Second, our approach overcomes most of the problems associated with the traditional sentiment measures. The data are collected in real time and represents a significantly large sample (thousands or even millions), while direct measures through surveys rarely exceed 5,000 respondents. Moreover, the data are provided from spontaneous actions rather than statements. Compared to indirect measures, this measurement technique circumvents the problem of a sentiment indicator endogenous to the stock market and economic activity. Third, this kind of measure captures the behavior of individual, i.e. less sophisticated investors, which reflects the philosophy of behavioral finance by including the opinions of imperfect people with social, cognitive and emotional biases.

Our analysis yields three important results. First, we find that our French sentiment index produces a faithful reproduction of the crashes during our study period. In addition, our French sentiment indicator correlates well with alternative sentiment measures largely used in the literature. Second, we show that our French sentiment indicator drives the behavior of mutual fund investors. Specifically, we find that higher sentiment index (i.e. pessimism) is significantly associated with outflows from equity funds and inflows to treasury bonds. Third, the Vector Autoregression (VAR) analysis reveals evidence about short-run predictability in return. An increase in our sentiment index leads to short-term return reversal. The reversal pattern is more pronounced for smaller firms than larger firms, consistent with the predictions of noise trader's models.

\footnotetext{
${ }^{1}$ Other studies examine exogenous and non-economic factors affecting investor mood such as sunshine (Hirschleifer and Shumway, 2003), sport (Edmans et al., 2007) or earthquake (Shan and Gong, 2012).

${ }^{2} \mathrm{http}: / /$ www.google.com/trends
} 
Our research is organized as follows. The second section is devoted to a summary of existing studies using Google search volume data. The third section develops our measurement of French investor sentiment. The fourth section presents the econometric method and analyses the empirical results obtained. The fifth section concludes the study.

\section{Literature Review}

Google search volume data have attracted the attention of researchers both in social and experimental sciences. In natural sciences for instance, access to internet users' queries has been vital in developing a public health tool. Ginsberg et al. (2009), through the use of Google search engine and internet user queries, are able to track the progression of influenza within the U.S. This approach allows for faster data gathering for influenza surveillance: instead of one to two weeks, measures are available within a day. This form of information gathering is also widely used in social sciences. In political science, for instance, Ripberger (2011) questions the value of using Google Trends to measure public attention. He compares the traditional measure of political science to the evolution of media coverage on a subject with the number of queries related to the same subject on the Internet. His results show that both measures are strongly related.

In the field of economics, Goel et al. (2010) note that the internet search volume helps predict consumer behavior by forecasting box office ticket sales for weekend films, or song rankings on the billboard music charts. They indicate that the usefulness of this indicator does not lie in its superiority over other indicators, but is related to its almost immediate availability and accessibility. McLaren (2011) uses the internet search volume as predictors of the labor and housing markets. He concludes that internet search data are becoming a useful source of information about the outlook for the economy of the United Kingdom.

In the field of finance, Da et al. (2011a) are the first to use the search volume data presented though Google to assess the degree of attention paid by investors for certain stocks. Specifically, they test and validate the hypothesis of Barber and Odean (2008) that when investors are net buyers of attention-grabbing stocks, they invite attention on these stocks and exert an upward pressure on their prices. In addition, they stress the interest of internet search volume: the volume of requests is a revealed measure of attention. If the internet search volume carries a negative connotation, investors are pessimistic. In another study, Da et al. (2011b) use search queries related to household concerns to measure retail investor sentiment. Their results are similar to other studies that consider the role of investor sentiment in the stock market. They find that this US search-based measure has predictive power on stock returns, stock market volatility and fund flows.

Other recent studies highlight the usefulness of search data for predictability. Dzielinski (2011) establishes that a measure of economic uncertainty based on the frequency of internet searches is useful for predicting stock returns and volatility. Drake et al. (2011) suggest that the amount of information asked by investors about a firm allow them to partially anticipate the information content of the earnings announcement. Bank et al. (2011) show that an increase in search queries is associated with an increase in trading activity and stock liquidity. Smith (2012) evidences that the number of Google Internet searches for particular keywords helps predict the volatility in the market for foreign currency. This paper seeks to empirically test if search engine query data offer insights into the French stock market. Indeed, most prior research on the effects of sentiment almost exclusively focuses on results for the U.S. stock market. 


\section{The development of the sentiment index}

The approach developed in this paper is similar to that presented by Da et al. (2011b), although it also has a number of significant differences. The first step of our analysis begins by identifying the terms searched by individuals to express their outlook about the economic situation. To achieve this goal, we use the categories defined by the General Inquirer Harvard IV-4 dictionary largely used in finance literature to perform textual content analysis ${ }^{3}$. Since our goal is to proxy investor's pessimism, we consider the lists of terms in the categories "economy" and "negative". The intersection of these two lists leads to a "starting list" of 63 economic and negative terms ${ }^{4}$.

Several reasons justify the choice of the categories "economy" and "negative". On the one hand, investor sentiment surveys ask individuals about their perception of economic conditions. On the other hand, as shown by textual analytic literature in finance, negative words best capture the psychological intuition behind investor sentiment ${ }^{5}$. This analysis is consistent with established finding in the field of psychology supporting the idea that "bad is stronger than good"; people react more strongly to a negative phenomenon than to a positive one. Simonton and Baumeister (2005) indicate that this type of human reaction needs to be qualified as one of the fundamental, basic, universal and general truths in psychology. Garcia (2012) also states that investors use different decision rules in boom than in bust, while being especially sensitive to news during downturns.

The proposed measure implicitly relies on the fact that people collect information on the Internet using search engines. In a laboratory experiment, Holscher and Strube (2000) attempt to understand how individuals proceed to research economic concepts using the Internet. Their results indicate that if individuals are not simultaneously experts in economics and the Internet, they overwhelmingly use a search engine. Jansen and Spink (2006) conduct a metaanalysis of articles from a very large database of queries. Their results show that one third of queries on the Internet use only one term and that operators such as and/or are rarely used. These studies suggest that a measure of investor sentiment from a query of a specific term with a search engine is consistent with the observed behavior of Internet users.

Two elements distinguish our approach from that of Da et al. (2011b). First, we attempt to avoid inflating the explanatory power of the terms introduced in the Principal Component Analysis performed to extract our measure of sentiment. Specifically, we do not expand the initial list of words by adding qualifiers, e.g. we do not search for inflation, inflation rate or core inflation. Second, we use the search volumes from Google Trends rather than the measure of Google Insights For Search used by Da et al. (2011b). This may seem trivial, but is actually quite important as the measures differ depending on the search engine. Whatever the measure, the search volume index is normalized in the same way. However, the scaling differs depending on the search engine: Google Insights For Search normalizes values by the highest point, while Google Trends uses the average traffic associated with the term sought (fixed scaling: the starting date of data availability (i.e. January 2004) as benchmark value; relative scaling: the data is scaled to the average search traffic during the time period for

\footnotetext{
${ }^{3}$ We choose to use the General Inquirer because it allows us to identify terms that can be categorized and according to their valence, i.e. positive or negative terms. Indeed, French linguists indicate that such categorization of terms according to their valence does not exist in French (Vincze and Bestgen, 2011).

4 The terms identified were then translated in French using different translators (Google Translation and Reverso). Moreover, almost all of the words retained in our analysis can be found in French economic thesaurus, like "Delphe", "Eurovoc" and "OECD Thesaurus".

${ }^{5}$ See, for example, Tetlock (2007).
} 
which data is requested.). Google Trends approach is thus superior as it avoids the hindsight bias when we use fixed scaling.

The "starting list" of 63 French terms is reduced to a list of 8 terms. First, we download the weekly search index volumes pertaining to the "starting list" of terms between January 4, 2004 and December 25, 2011. Each French term has been introduced in Google Trends by limiting the geographic scope to France in order to measure the French investor sentiment. We eliminate terms not widely searched with a history of at least 96 consecutive weeks. Second, since our focus is individual investor sentiment, we retain only terms with a familiar general economic meaning rather than those with a specific signification. To do this, we search every term with Google Insights For Search. This search engine allows to classify internet searches by category and to identify the most frequent searches associated with the term analyzed ${ }^{6}$. When the most frequent searches attest to the fact that French internet users do not give to the term analyzed a regular economic definition, we remove the term from our list ${ }^{7}$. Ultimately, this work leads to the following list of the French search terms: "faillite", "débiteur", "déficit", "inflation", "liquidation", "pauvreté", "récession" and "crise". These terms correspond respectively in English language to the words: bankruptcy, debtor, deficit, inflation, liquidation, poverty, recession and crisis.

\section{Figure 1: Google trends negative sentiment index}

This figure displays the development of the Google trends negative sentiment index (GTNS) from January 04, 2004 to December 25, 2011.

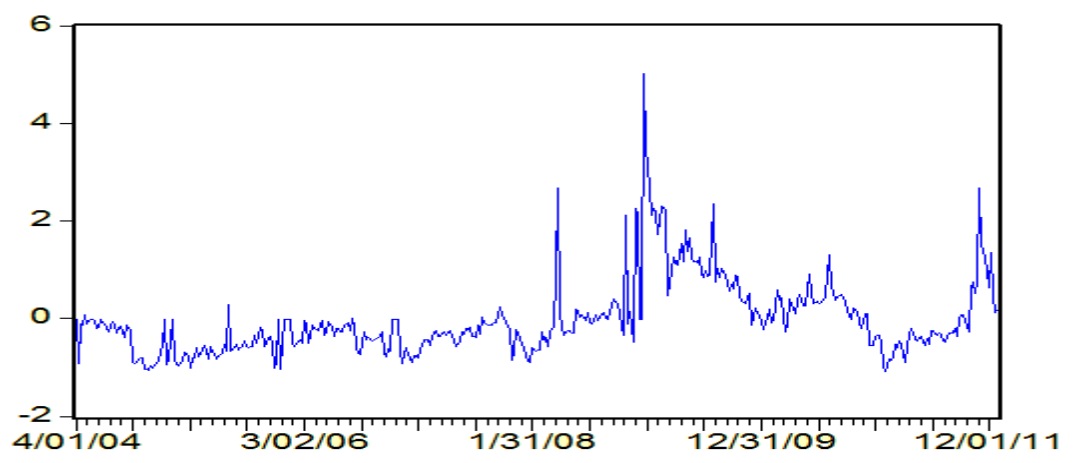

Since each word is likely to include a sentiment component as well as an independent idiosyncratic component, we apply a principal component analysis on the eight search terms retained to isolate the component sentiment. The main objective is to summarize, as efficiently as possible, into a single indicator the common information contained in the set of search terms. In the same way as Da et al. (2011b), we remove the effects of seasonality contained in the Google search volume time series, by using the residual terms from the regression of each time series on week dummies and month dummies. Our sentiment measure represents the first principal component based on the correlation matrix of the eight selected

\footnotetext{
${ }^{6}$ In September 2012, Google announced the release of a new version of Google Trends combining the features of Google Insights For Search and Google Trends. The new version provides only data scaled by the highest point. Notice, however that Google Correlate provides data normalized with fixed scaling system but expressed in different units.

${ }^{7}$ For example, we keep the word "crisis", as it is associated with searches such as "financial crisis" or "economic crisis". However, we exclude the word "depression" because it is often connected in French language with medical terms such as "nervous breakdown" or "depression symptoms."
} 
seasonally-adjusted terms. We obtain the following Google Trends Negative Sentiment index (GTNS):

$$
\begin{aligned}
\text { GTNS }_{\mathrm{t}}=0.745 & \text { bankruptcy }_{\mathrm{t}}+0.406 \text { debtor }_{\mathrm{t}}+0.615 \text { deficit }_{\mathrm{t}}+0.417 \text { inflation }_{\mathrm{t}} \\
& +0.467 \text { liquidation }_{\mathrm{t}}+0.402 \text { poverty }_{\mathrm{t}}+0.661 \text { recession }_{\mathrm{t}} \\
& +0.776 \text { crisis }_{\mathrm{t}}
\end{aligned}
$$

The principal component analysis reveals three dimensions that explain approximately $62 \%$ of the total variance of the common factor. The first component summarizes the most significant variation, alone it accounts for about $36 \%$ of the variance. The terms "bankruptcy", "deficit", "recession" and "crisis" get a relatively large weight in the equation. These terms are thus closely related to investor sentiment. Moreover, the coefficients of the different terms all display the expected positive signs. Indeed, the internet search volume associated with a term is inversely related to individuals' state of mind.

Figure 2 shows levels of the GTNS and the alternative sentiment indices. The VIX index goes up and down well with GTNS. As expected, the two series are positively and highly correlated. The coefficient of correlation is 0.741 and statistically significant at $1 \%$. The CCI also exhibits a high degree of co-movement with the GTNS. The correlation between GTNS and CCI is -0.663 and significant at $1 \%$. The negative correlation supports that our sentiment indicator adequately captures the (bearish) sentiment of retail investors. We also regress the CCI on the one-month lagged GTNS index. Results show that the GTNS significantly predicts a decrease in future CCI (t-statistic $=-6.84$ ). Granger causality tests we conducted (not reported) support this finding, the direction of influence running from GTNS to CCI, but not the other way. This result is consistent with the fact that Google data leads survey data by at least one month ${ }^{8}$.

\section{Figure 2: Google trends negative sentiment vs. alternative sentiment measures}

These graphics display the development of Google Trends Negative Sentiment index (GTNS) against two alternative sentiment measures: the implied volatility index (VIX) derived from CAC 40 options and the consumer confidence index (CCI) published by the French National Institute of Statistics and Economic Studies. The weekly sample (left graph) contains 417 observations from January 04, 2004 to December 25, 2001. The monthly sample (right graph) contains 96 observations from January 2004 to December 2011.
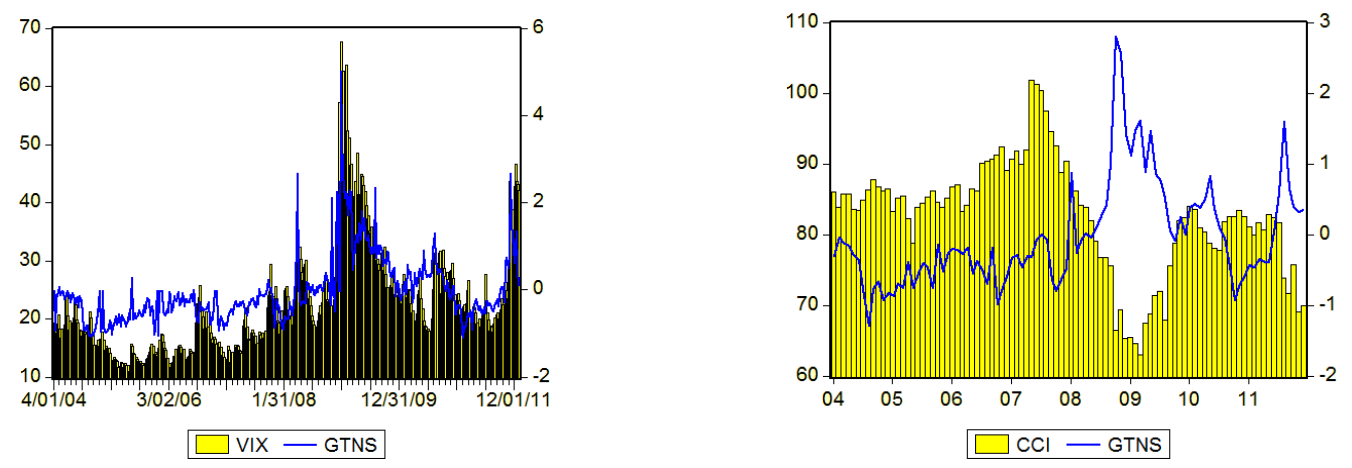

Recognizing that individual investors (i.e. noise traders) are significant holders and traders of mutual funds, a large number of papers investigate the relation between investor sentiment

\footnotetext{
${ }^{8}$ Results using the VIX as indicator of sentiment are similar. Results are available upon request.
} 
and mutual fund flows ${ }^{9}$. To examine the soundness of our sentiment measure, we estimate equation (2) using monthly observations.

$$
\text { Flow }_{i, t+k}=\alpha_{0}+\alpha_{1} \text { GTNS }_{t}+\sum_{m} \beta_{m} \text { Control }_{i, t}^{m}+\varepsilon_{i, t+k}
$$

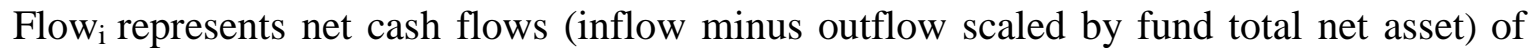
equity or bond mutual funds. Control is a set of control variables, namely the alternative sentiment measures VIX and CCI and five lags of market returns. Monthly VIX is calculated by averaging the weekly data available in the month. Monthly mutual fund flow data for the two groups of mutual funds are obtained from AFG-ASFFI between January 2008 and December 2011.

\section{Table 1: Relationship between GTNS and mutual fund flows}

This table presents the results of estimating the model (2). Fund flow represents the ratio inflow minus outflow scaled by fund total net asset for each category of funds. GTNS denotes the coefficient estimated on the sentiment variable. The coefficients on the control variables are not reported here to conserve space. The sample period includes monthly data from January 2008 to December 2011. ***, **, * indicate statistical significance at the $0.01,0.05$ and 0.10 level, respectively.

\begin{tabular}{cccccc}
\hline & Flow $_{\mathrm{t}+1}$ & Flow $_{\mathrm{t}+2}$ & Flow $_{\mathrm{t}+3}$ & Flow $_{\mathrm{t}+4}$ & Flow $_{\mathrm{t}+5}$ \\
\hline Panel A: Equity fund flow & & & & & -0.000 \\
\hline GTNS & $-0.003^{*}$ & $-0.009^{* *}$ & -0.001 & -0.001 & Yes \\
Control variables & Yes & Yes & Yes & Yes & 0.112 \\
Adj. R-squared & 0.115 & 0.114 & 0.112 & 0.113 & \\
\hline Panel B: Bond fund flow & & & & & 0.000 \\
\hline GTNS & 0.005 & $0.004^{* *}$ & 0.001 & Yes & Yes \\
Control variables & Yes & Yes & Yes & 0.007 & 0.006 \\
Adj. R-squared & 0.057 & 0.092 & 0.006 & \\
\hline
\end{tabular}

The results of the regression are displayed in Table $1^{10}$. Our results show that GTNS exhibits significant predictive power for equity and bond mutual fund flows for month $\mathrm{k}=2$. Indeed, GTNS predicts outflows from equity funds and inflows in bond funds. When negative sentiment is high, investors sell equity funds and purchase bond funds with the proceeds: this seems to be a substitution effect. Notice however, that results must be interpreted with caution due to the short period of analysis which covers only 4 years of monthly data.

\section{Impact of investor sentiment on stock returns}

According to investor sentiment theory, sentiment is an excellent market timing indicator. Proponents of behavior finance theory consider that noise traders overvalue stocks in optimistic sentiment periods and undervalue them in pessimism sentiment periods. Since prices eventually return to their fundamental value, high level of optimism (pessimism) predicts low (high) future returns. In addition to the theoretical framework, when the market peaked, sentiment indicators often show a record level. Stock market returns and investor sentiment may act as system. To study the dynamic link between investor sentiment and stock returns, a VAR model is appropriate. The VAR model not only highlights the dynamic interactions between the variables, but also measures the speed, scope and duration of the

\footnotetext{
${ }^{9}$ See, for example, the recent study of Ben-Rephael et al. (2012).

${ }^{10}$ For succinctness only the coefficients of the variable sentiment are presented.
} 
impact of sentiment on returns via the impulse response functions. We express the VAR model as:

$$
Y_{t}=\mu+\sum_{i=1}^{P} \emptyset_{i} Y_{t-i}+\varepsilon_{t}
$$

Where $Y_{t}$ is the column vector containing: GTNS, $R_{\text {small }}$ and $R_{\text {large }} . \mu$ is the vector of constant terms. $\Phi_{i}$ is the matrix of coefficients. $\varepsilon_{t}$ is the vector of random error terms and $p$ is the optimal number of lags determined by minimizing the Akaike information criterion and the Schwarz criterion ( $p=2$ in our case).

Since previous studies show that the effect of investor sentiment is not uniform across all stocks, we consider two size-ranked portfolios ${ }^{11}$. Indeed, the sentiment effect is stronger among stocks whose valuations are highly subjective and difficult to arbitrage (e.g. small stocks). The first portfolio (small) contains the 30 percent of all stocks that have the smallest market value and the second (large) contain the 30 percent of all stocks that have the largest market value. Stocks are allocated to each portfolio in June of year $t$ and rebalanced annually. The return of each portfolio is the value-weighted mean of stock returns. Stock returns and market capitalizations are collected from Datatstream.

\section{Table 2: Summary statistics}

This table provides summary statistics for the data used in the study. ADF is the augmented Dickey-Fuller (1979, 1981) unit-root test and PP is the Phillips-Perron (1988) unit-root test that a variable has a unit root. GTNS represents the Google trends negative sentiment index. $R_{\text {small }}$ represents the returns of portfolio with the smallest market capitalization and $\mathrm{R}_{\text {large }}$ represents the returns on the portfolio with the largest market capitalization. VIX is the implied volatility derived from CAC 40 options. CCI is the consumer confidence index published by the French National Institute of Statistics and Economic Studies. The sample period includes weekly data (monthly data for CCI) from January 4, 2004 to December 25, 2011.***, **, * indicate statistical significance at the $0.01,0.05$ and 0.10 level, respectively.

\begin{tabular}{lccccc}
\hline & Obs & Mean & Std.dev & ADF & PP \\
\hline GTNS & 417 & 0 & 1 & $-6.056^{* * *}$ & $-6.112^{* * *}$ \\
$\mathrm{R}_{\text {small }}$ & 417 & 0.004 & 0.021 & $-9.953^{* * *}$ & $-15.946^{* * *}$ \\
$\mathrm{R}_{\text {large }}$ & 417 & 0.001 & 0.029 & $-23.090^{* * *}$ & $-23.042^{* * *}$ \\
VIX & 417 & 22.689 & 9.428 & $-2.894 * *$ & $-2.949 * *$ \\
CCI & 96 & 82.552 & 7.956 & -1.315 & -1.189 \\
\hline
\end{tabular}

Table 2 reports the results of unit root tests using Augmented Dickey Fuller and PhillipsPerron $^{12}$. The GTNS and stock returns time series appear to be stationary, and both tests reject the null hypothesis of non-stationarity at the $1 \%$ level. The results from estimating weekly VAR model are presented in Panel A of Table 3. There is very limited evidence that investor sentiment is influenced by previous stock returns. Only past large returns negatively influence present investor sentiment. The significant effect is concentrated on the second lag. An increase in past large returns is associated with a decrease in GTNS (i.e. individuals more optimistic). It seems that French individuals behave as positive-feedback traders, traders who forecast continuations of past returns. However, the Granger causality F-statistic indicates that past stock returns (small and large stocks) provide insignificant information about present investor sentiment.

\footnotetext{
${ }^{11}$ See, for example, Baker and Wurgler $(2006,2007)$

12 The inclusion of larger lag numbers and drift/trend terms in the unit root test equations does not change these results.
} 
As expected, small returns are significantly influenced by investor sentiment. Results show a significant negative relationship between investor sentiment lagged one week and small returns. Results are reversed when investor sentiment is delayed by two weeks; a significant positive relationship is now observed. The same phenomenon, but of lesser magnitude, is observed for large returns ${ }^{13}$. It seems that small returns are more vulnerable to investor sentiment than large returns. The Granger causality F-statistic shows that the null hypothesis that investor sentiment does not cause stock returns is rejected at the $1 \%$ level.

\section{Table 3: VAR model estimation results}

This table presents the estimations result of Vector Autoregression model with 2 lags. Panel A reports the coefficient estimates, Panel B the results of Granger Causality tests and Panel $\mathrm{C}$ the long run forecast error variance decomposition (10 weeks). In Panel C, P-values testing that coefficients or forecast error decompositions are different from zero, are given in parentheses. The data cover 417 weekly observations from January 4, 2004 to December 25, 2011.***,**, * indicate statistical significance at the 0.01, 0.05 and 0.10 level, respectively.

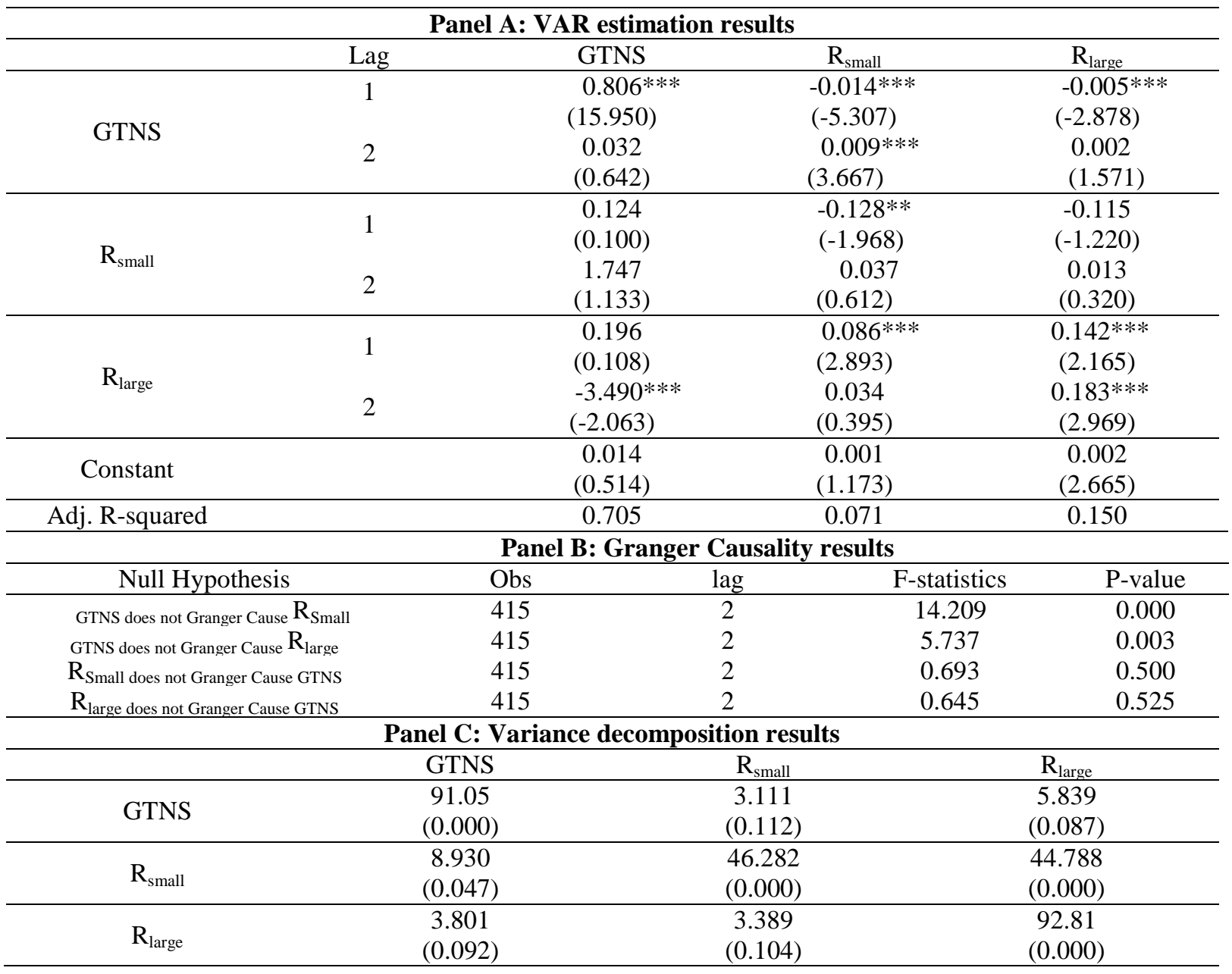

Similarly to Brown and Cliff (2004), we use both the levels and the changes of the variable GTNS when calibrating equation (3). Theoretically speaking, both levels and changes in sentiment should impact market returns. Indeed, when investor sentiment decreases from very bullish to bullish, one might expect a positive return as sentiment is still bullish or a reduction in the return as sentiment has decreased. Results (not reported) are

\footnotetext{
${ }^{13}$ We also used a broad market index (CAC 40) before the split into small and large caps and found that results are identical to those using large caps, i.e. sentiment does not influence stock index returns.
} 
virtually identical. We operate similarly with the variable Flow $_{\mathrm{i}}$ in equation (2), by proceeding with the changes of the variable GTNS. Again, results are essentially the same.

The VAR model does not provide guidance as to the interpretation of dynamic properties of the system. As noted by Sims (1980), it is challenging to concisely interpret autoregressive systems. The estimated coefficients on the successive lags have the tendency to fluctuate and ambiguous cross-equation feedbacks are sometimes observed. Further, as the t-tests of the individual coefficients may not be reliable, they may not reveal the correlations between the variables. Sims (1980) thus recommends the analysis of a variable response to a shock in another variable via impulse response functions.

\section{Figure 3: Impulse response functions}

The graphs represent the impulse response functions. The dashed lines represent the upper and lower bands of the confidence interval obtained using Monte Carlo simulation. The responses are statistically significant at the $5 \%$ level when the upper band and lower band have the same sign. The horizon is on the horizontal axis and the percentage returns are on the vertical.
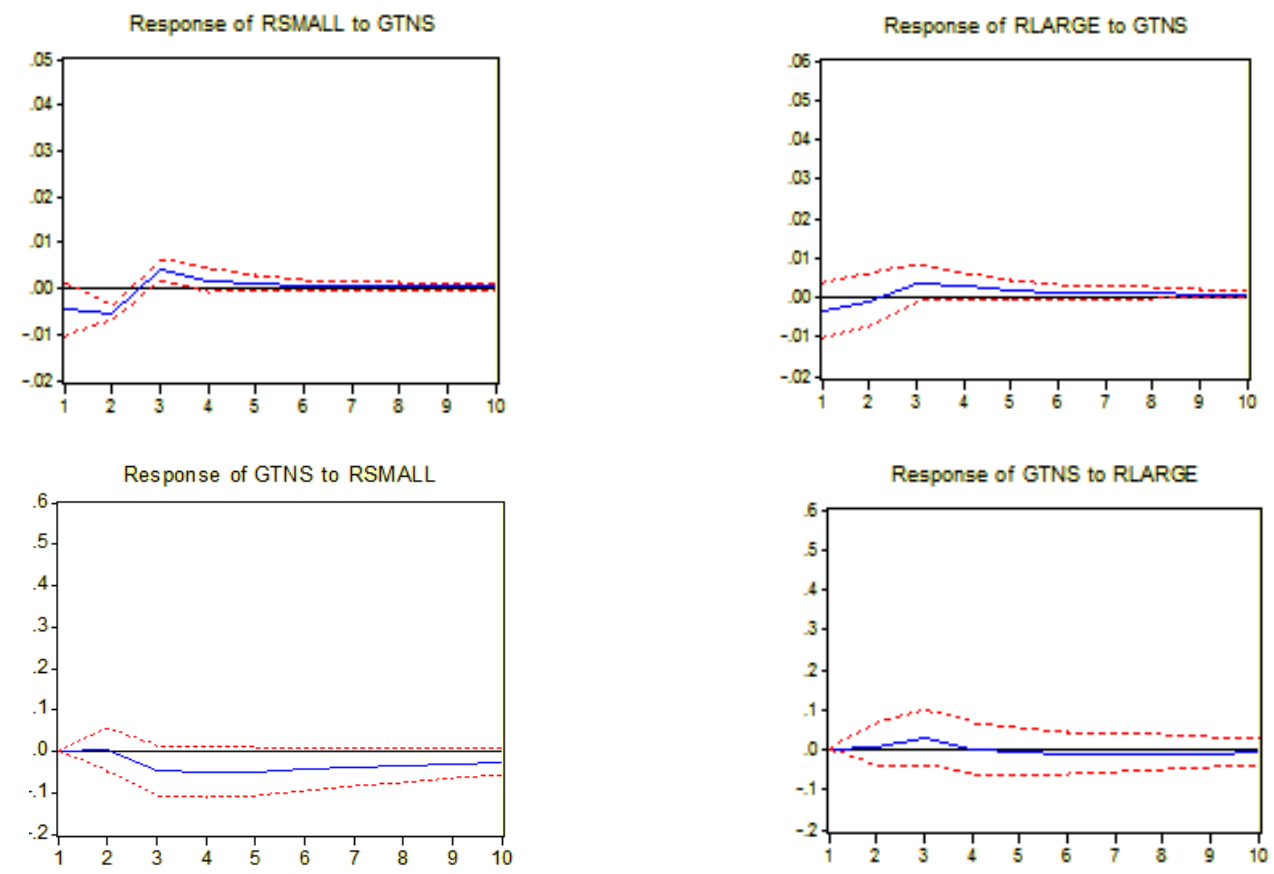

Figure 3 depicts the impulse response functions exemplifying two types of reaction: (i) the responses of stock returns to a one-time standard deviation increase in investor sentiment; and (ii) the responses of investor sentiment to a one-time standard deviation increase in stock returns. The Choleski order is set to be GTNS, $R_{\text {small }}$ and $R_{\text {large. }}$ Changing the order does not affect the results ${ }^{14}$. Figure 3 shows that the response of small returns to one standard deviation shock in investor sentiment is negative (insignificant during the first week) during the two first weeks but becomes positive and significant in the third week. The significant effect of investor sentiment on small returns is consistent with sentiment-induced short-term mispricing. Indeed, high level of our negative sentiment indicator induces downward pressure in stock prices followed by a return to fundamental levels. Large returns show a weaker dependence to one shock in investor sentiment. The response of large returns is insignificant and of relatively smaller magnitude than those of small returns. A shock on stock

\footnotetext{
${ }^{14}$ We also used the generalized impulses technique which is not sensitive to variable ordering. Findings are similar to those obtained with Choleski's decomposition.
} 
returns has no immediate effect on the sentiment indicator. The insignificant response is not noticeable until the second period and quickly fades over time.

Although, it is possible that the impact of GNTS on market returns is related to the rational investor uncertainty, as suggested by Dzielinski (2011), our findings are better explained by behavioral finance approach. Dzielinski (2011) considers that internet searches reported by Google Trends impact aggregate stock returns as they capture rational investor uncertainty about the state of the economy. Behavioral finance on the other hand, postulates that the defining feature of investor sentiment is that it leads to mispricings which are subsequently corrected. We find that the effect of GTNS reverses over the following weeks, supporting a non-rational attitude. Furthermore, the reversal is quantitatively large, in the sense that the majority of initial drift disappears over four weeks.

Panel $\mathrm{C}$ of Table 3 presents the long-run variance decomposition generated from the VAR model of stock returns and investor sentiment. In the case of small returns, approximately $9 \%$ of its the forecast error variance is explained by investor sentiment. The contribution of investor sentiment to the variance of small returns is significant and non-negligible. In contrast, less than $4 \%$ of the forecast error variance of large returns is explained by investor sentiment. This finding suggests that small returns are more endogenous to investor sentiment than large ones. The contribution of stock returns to the variance of investor sentiment is moderate: almost $6 \%$ of the forecast error variance is explained by large returns and approximately $3 \%$ by small returns. Thus, a shock on sentiment has greater impact on returns than a shock on returns will have on sentiment.

\section{Conclusion}

In this paper, the main objective is to propose a novel measure of French investor sentiment based on the search volume data from Google Trends and to investigate its impact on the stock market. This approach avoids many of the limitations associated with traditional sentiment measures by better detecting investor's mood. It appears that our sentiment indicator lines up with recognized crashes during the period analyzed and also correlates well with alternative sentiment measures often used in the literature. Furthermore, we find that investor sentiment influences the behavior of mutual fund investors. An increase in investor sentiment leads to significant outflows from equity fund flows and inflows in bond funds.

The results from our empirical tests show that investor sentiment contributes to predict short-term market returns. The results of the impulse response functions generated from VAR model reveal a negative relation between investor sentiment and stock returns during the first 2 weeks. The relation then reverses and becomes positive over the next 3 to 4 weeks. Moreover, we find that the relation is stronger for smaller firms than larger firms. Our results provide support to models based on noise trader sentiment, suggesting that investor sentiment creates return reversals particularly for stocks that are difficult to arbitrage and hard to value.

\section{References}

Baker, M and J. Wurgler (2006) "Investor Sentiment and the Cross-Section of Stock Returns." Journal of Finance 61, 1645-1680.

(2007) "Investor Sentiment in the Stock Market." Journal of Economic Perspectives $21,129-151$. 
Bank, M., L. Martin and G. Peter. (2011) "Google Search Volume and Its Influence on Liquidity and Returns of German Stocks." Financial Markets and Portfolio Management 25, 239-64.

Barber, B.M and T. Odean. (2008) "All That Glitters: The Effect of Attention and News on the Buying Behavior of Individual and Institutional Investors." Review of Financial Studies 21, 785-818.

Barberis, N., A. Shleifer and R. Vishny (1998) “A Model of Investor Sentiment." Journal of Financial Economics 49, 307-343.

Ben-Rephael, A., S. Kandel and A. Wohl. (2012) "Measuring Investor Sentiment with Mutual Fund Flows." Journal of Financial Economics 104, 363-382.

Black, F. (1986) “Noise.” Journal of Finance 41, 529-543.

Brown, G.W and M.T. Cliff (2004) "Investor Sentiment and the near-Term Stock Market." Journal of Empirical Finance 11, 1-27.

Da, Z., J. Engelberg and P. Gao (2011a) "In Search of Attention." Journal of Finance 66, 1461-99.

Da, Z., J. Engelberg and P. Gao (2011b) "The sum of all FEARS: investor sentiment and asset prices." Unpublished Working Paper.

De Long, J.B., A. Shleifer, L.H. Summers and R.J. Waldmann (1990) "Noise Trader Risk in Financial Markets.” Journal of Political Economy 98, 703-738.

Dickey, D and W. Fuller (1979). "Distribution of the Estimators for Autoregressive Time Series With a Unit Root." Journal of the American Statistical Association 74, 427431.

Dickey, D and W. Fuller (1981) "Likelihood ratio statistics for autoregressive time series with unit root." Econometrica 49, 1057-1072.

Drake, S., D. Roulstone and J. Thornock (2012) "Investor Information Demand: Evidence from Google Searches Around Earnings Announcements." Journal of Accounting Research 50, 1001-1040.

Dzielinski, M. (2011) "Measuring Economic Uncertainty and Its Impact on the Stock Market." Finance Research Letters 9, 167-175.

Edmans, A., D. Garcia and Ø. Norli (2007). “Sports Sentiment and Stock Returns.” Journal of Finance 62, 1967-1998.

Garcia, D. (2012) “Sentiment during recessions.” Journal of finance, forthcoming.

Ginsberg, J., M. Mohebbi, R. Patel, L. Brammer, M. Smolinski and L. Brilliant (2009) "Detecting influenza epidemics using search engine query data." Nature 457, 10121014. 
Goel, S., J.M. Hofman, S. Lahaie, D.M. Pennock and D.J. Watts. (2010) "Predicting Consumer Behavior with Web Search." PNAS Proceedings of the National Academy of Sciences of the United States of America 107, 17486-17490.

Hirshleifer, D and T. Shumway (2003) "Good Day Sunshine: Stock Returns and the Weather." Journal of Finance 58, 1009-1032.

Holscher, C and G. Strube (2000) "Web Search Behavior of Internet Experts and Newbies." Computer Networks 33, 337-346.

Jansen, B.J and A. Spink (2006) "How Are We Searching the World Wide Web? A Comparison of Nine Search Engine Transaction Logs." Information Processing \& Management 42, 248-263.

King, G. (2011) "Ensuring the Data-Rich Future of the Social Sciences." Science 331, 719721.

Lazer, D., A. Pentland, L. Adamic, A. Sinan, A.L. Barabàsi, D. Brewer, N. Christakis, N. Contractor, J. Fowler, M. Gutmann, T. Jebara, G. King, M. Macy, D. Roy and V.A, Marshall. (2009) "Computational Social Science." Science 323, 721-723.

McLaren, N. (2011) "Using Internet Search Data as Economic Indicators." Bank of England Quarterly Bulletin 51, 134-140.

Phillips, P and P. Perron (1988) "Testing for a unit root in time series regression." Biometrica 75, 335-346.

Ripberger, J.T. (2011) "Capturing Curiosity: Using Internet Search Trends to Measure Public Attentiveness.” Policy Studies Journal 39, 239-259.

Shan, L and S.X. Gong (2012) "Investor sentiment and stock returns: Wenchuan earthquake." Finance Research Letters 9, 36-47.

Simonton, D.K and R.F. Baumeister (2005) "Positive Psychology at the Summit." Review of General Psychology 9, 99-102.

Sims, C. (1980) "Macroeconomics and Reality." Econometrica 48, 1-48.

Smith, G.P. (2012) "Google Internet Search Activity and Volatility Prediction in the Market for Foreign Currency." Finance Research Letters 9, 103-110.

Tetlock, P.C. (2007) "Giving Content to Investor Sentiment: The Role of Media in the Stock Market” Journal of Finance 62, 1139-1168.

Vincze, N., and Y. Bestgen (2011) "Identification de mots germes pour la construction d'un lexique de valence au moyen d'une procédure supervisée", Actes de TALN11 1,223234. 